16 Pyrtek LJ, Bartus SA. Hepatic pyaemia. N Engl f Med 1965;272:551-4.

1: McFadzean AJS, Chang KPS, Wong CC. Solitary pyogenic abscess of liver treated by closed aspiration and antibiotics. A report of 14 consecutive cases with recovery. Br F Surg 1953;41:141-52.

${ }^{18}$ Sherman JD, Robbins SL. Changing trends in the casuistics of hepatic abscess. Am 7 Med 1960;28:943-50.

${ }^{19}$ Block MA, Schuman BM, Eyler WR, Truant JP, Du Sault LA. Surgery of liver abscesses. Use of newer techniques to reduce mortality. Arch Surg $1964 ; 88: 602-9$

2" Patterson DK, Ozeran RS, Glantz GJ, Miller AB, Finegold SM. Pyogenic liver abscess due to microaerophilic streptococci. Ann Surg 1967; $165: 362-76$.
${ }^{21}$ Bateman NT, Eykyn SJ, Phillips I. Pyogenic liver abscess caused by Streptococcus milleri. Lancet $1975 ;$ i :657-9.

22 Reid TMS, Davidson AI. Streptococcus milleri liver abscesses. Lancet $1976 ; \mathrm{i}: 648-9$.

${ }^{23}$ Verlenden WL, Frey CF. Management of liver abscess. Am $\mathcal{f}$ Surg $1980 ; 140: 53-9$.

24 Young AE. The clinical presentation of pyogenic liver abscess. $\mathrm{Br} \mathfrak{f}$ Surg $1976 ; 63: 216-9$.

${ }^{25}$ Scully RE, Galdabini JJ, McNeely BU. Clinicopathological exercise: case 31-1980. N Engl f Med 1980;303:325-31.

(Accepted 15 fuly 1981)

\title{
Ingrowing toenails: an evaluation of two treatments
}

\author{
P F CAMERON
}

\begin{abstract}
Most of the procedures used for treating ingrowing toenails cause considerable discomfort and have high failure rates. This study evaluated two methods of treatment: (a) a simple procedure, and (b) angular phenolisation. Patients were seen in a special toenail clinic and were assessed for severity and duration of symptoms. Those with no permanent deformity of the nail fold and with only minor infection were treated by the simple procedure. The nail was nicked and torn down to expose the infected nail fold. The patients were then taught to clean the area, spray it with povidone-iodine dry powder, and pack the nail fold with a twist of cottonwool. Patient; with recurrent or severe ingrowing toenails were treated by angular phenolisation. One hundred patients were treated by the simple procedure and 61 of these had had no recurrence after six months. A total of 280 phenolisations were carried out over 18 months and 272 were successful.
\end{abstract}

The treatments described are simple, effective, and well tolerated and should be considered as alternatives to traditional treatment.

\section{Introduction}

The ingrowing toenail is largely a disease of civilised society. Those who wear no shoes or who make their own do not appear to suffer from the condition. The increasing use of man-made fibres in socks and of plastic materials in shoes adds to the problem, as does the cost of footwear in general. Toes need a soft flexible toebox to the shoe (except where there is risk of injury) and adequate ventilation.

The current methods available for treating ingrowing toenails are generally unsatisfactory. ${ }^{1}$ Cutting a notch in the centre of the nail is traditional but largely ineffective. Ointments and creams induce maceration. Silver nitrate reduces a granuloma but does not remove the cause of the underlying infection and it renders the nail black, opaque, and friable, making future treatment difficult. Simple avulsion has been adequately condemned and should not be used as a method of treatment. Zadik's operation

Accident and Emergency Department, Queen Alexandra Hospital, Portsmouth

P F CAMERON, MB, BS, clinical assistant and general practitioner and wedge resection require time and a fair degree of skill; aseptic techniques are necessary and tissue planes are crossed. Patients undergoing these procedures experience postoperative pain and need to spend time off work to recover. The recurrence rate after these procedures is from $16 \%$ to $28 \%$. A recent development has been the introduction of the plastic gutter, but each kit costs $£ 2 \cdot 30$, and a failure rate of $44^{\prime \prime}$ () has been shown. ${ }^{2}$

This study was designed to investigate the technical and administrative problems associated with the management of ingrowing toenails and to evaluate two methods of treatment: (a) a simple procedure which could be used by general practitioners, chiropodists, and school nurses; and (b), for more severe cases, angular phenolisation.

\section{Patients and methods}

Most patients attending the accident and emergency department of this hospital (resident catchment population 518000 ) with toenail problems were referred to a special toenail clinic. Patients were seen at five-minute intervals during the first two hours of the clinic session for assessment, simple treatment, or review. During the second twohour session up to six patients were treated under ring block at 15minute intervals. These arrangements proved sufficient to cope with new patients without creating a waiting list. Clerical work was dealt with by the accident and emergency department clerks in the normal course of their duties, and one state-enrolled nurse employed for two and a half hours was sufficient for laying up, dressing, and clearing away.

Two methods of treatment were used.

\section{SIMPLE TREATMENT PROCEDURE}

Patients who had been experiencing symptoms for one month or less without permanent deformity of the nail fold and with only mild infection were treated by the simple procedure.

Firstly, debris was removed with $1 \%$ Savlon solution. The nail was then nicked using $12 \mathrm{~cm}\left(4 \frac{1}{2}\right.$ inch) nail pliers (fig $\left.1(a)\right)$ and torn down (fig $1(b)$ ) to expose the infected nail fold. The nail usually tears true, and because the nail is already undermined by infection the pain caused is less than that caused by a ring-block injection. The patients were instructed and shown how to clean the area twice daily with $1 \%$ Savlon solution and to spray the area with povidone-iodine dry powder spray (Disadine DP; Stuart Pharmaceuticals). They were shown how to pack the nail fold firmly with a twist of cotton-wool (fig $1(c)$ ) to prevent the fold collapsing inwards under shoe pressure until the nail grew out. They were also given advice on footwear and hygiene and were advised to abstain from physical education and field sports for one month. Finally, the patients were told to return for assessment after two to four weeks. If patients were then free from pain they were 
advised to dry pack the nail fold for three months. If the toe was still painful the simple procedure was repeated, and if this failed again phenolisation was carried out.
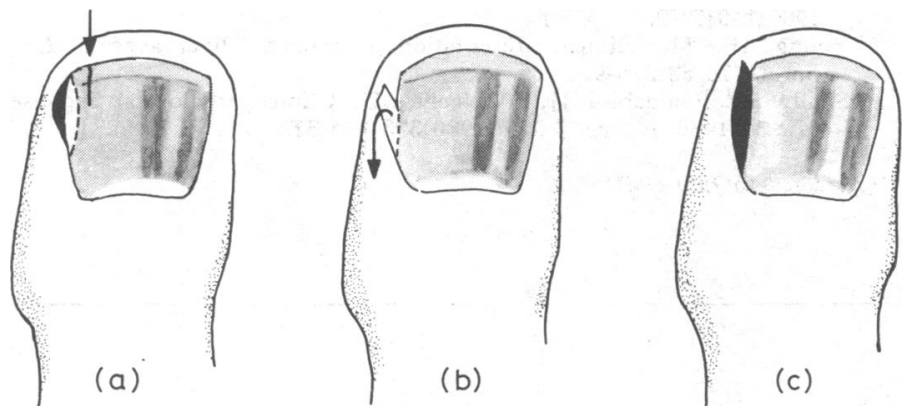

FIG 1 -Simple treatment procedure.

\section{ANGULAR PHENOLISATION}

Patients who failed to respond to the simple treatment procedure or who presented with a long history, proximal infections, or organisation of granulomatous tissue were treated by phenol cautery.

Firstly, ring block was induced by $2 \times 2 \mathrm{ml}$ plain lignocaine $2 \%$, and a rubber-band tourniquet was applied. Then the cuticle was separated from the nail for $3 \mathrm{~mm}$ from the side (fig $2(a)$ ) and the nail fold was excised to a point level with the side of the nail (fig $2(b)$ ). The toe was squeezed to remove surplus blood and residual granuloma was curetted. A sliver of nail was then cut with scissors down to the base and removed using "mosquito" forceps (fig $2(c)$ ), and a cotton bud soaked in liquefied phenol $(80 \%)$ was applied to the resulting cavity (fig $2(d)$ ). Care was taken to insert the phenol under the cuticle and to prevent spillage. A firm dry dressing was applied, the tourniquet removed, and the foot raised for about 15 minutes or until bleeding
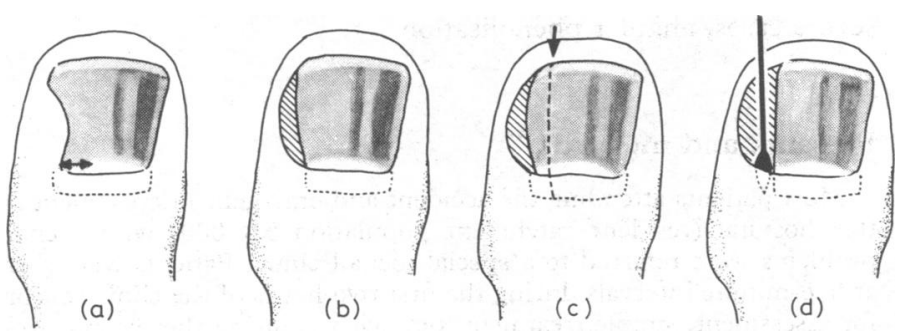

FIG 2-Angular phenolisation.

had stopped. The toe was then redressed with Melolin and Tubegauze and the patient was allowed home. The foot was rested for two days and then the dressing was changed in the accident and emergency department. From the fourth to seventh days patients were asked to clean the toe with Savlon and to apply a fresh piece of Melolin twice daily. Patients were told to return for assessment at seven days. Seven days after operation the healing area was cleaned, painted with mercurochrome $2 \%$, and redressed. At this stage any regrowth of granuloma can be suppressed with silver nitrate, but this was seldom found to be necessary. Patients were advised to apply a dry dressing during the day only until the toe was healed. Patients were told that they could resume bathing but were advised not to resume sports for three weeks.

\section{Results}

In the first year of the study 650 patients attended (mean 13.5 per session) and 188 were treated with phenol (mean 4.4 per session).

Simple treatment procedure-One hundred patients were entered in an open trial of this method of treatment. Most patients presenting were male teenagers (fig 3). Patients were followed up six months after discharge as this was judged sufficient time to allow regrowth of

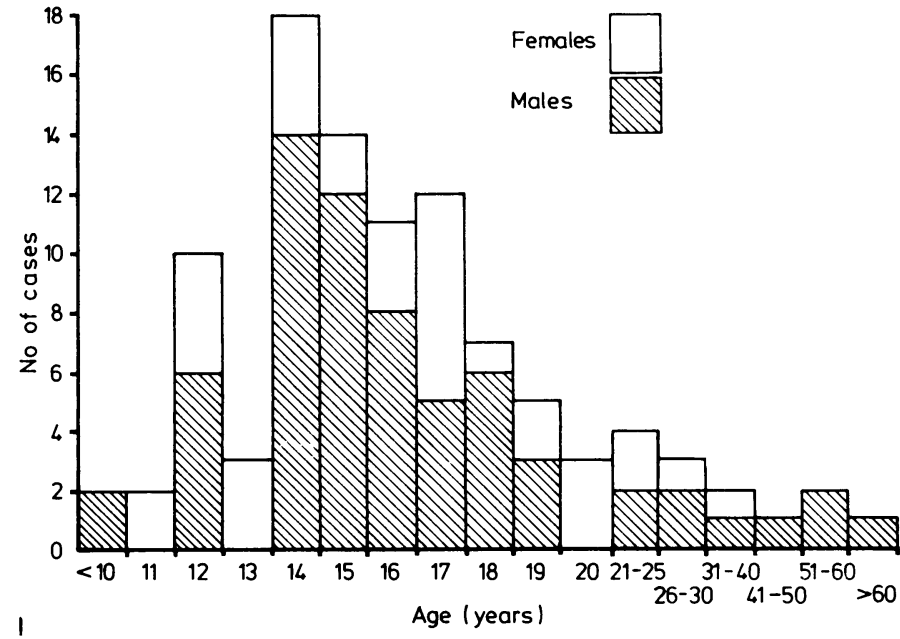

FIG 3-Age distribution of patients with uncomplicated ingrowing toenails.

fragments of nail removed. The results of treatment are shown in the table. Two patients were lost to follow up, and they have been included as treatment failures.

Phenolisation-A total of 280 phenolisations were carried out over 18 months. Only eight $(3 \%)$ patients required a second phenolisation excluding patients who returned with infection at the other side of the same toe or on the other foot.

Results of the simple procedure for treatment of ingrowing toenails

\begin{tabular}{ccc}
\hline $\begin{array}{c}\text { Duration of } \\
\text { symptoms before } \\
\text { treatment }\end{array}$ & $\begin{array}{c}\text { No of } \\
\text { patients }\end{array}$ & $\begin{array}{c}\text { No ("). with } \\
\text { no recurrence } \\
\text { at six months }\end{array}$ \\
\hline 2 weeks & 19 & $14(74)$ \\
$2-4$ weeks & 41 & $27(66)$ \\
$1-4$ months & 25 & $13(52)$ \\
4 months & 15 & $7(47)$ \\
\hline
\end{tabular}

\section{Discussion}

The simple treatment procedure described here has proved useful for the initial management of patients presenting with ingrowing toenails. Patients need to be encouraged to seek help early; at present many hold back for fear of avulsion. The only equipment required for this method is a pair of nail pliers (about $\left.f^{5}\right)$. The procedure can be learnt easily and carried out by general practitioners, chiropodists, and school nurses. Povidoneiodine dry powder spray was easy to apply accurately, it did not cause any skin maceration, and any residue was easily removed with Savlon liquid. Its broad antimicrobial spectrum of activity ensured prophylaxis against further infection during the healing process. No patients reported any allergic reactions to the spray.

For resistant or severe cases, angular phenolisation is the method of choice. It is effective with a low incidence of recurrence. The procedure can be learnt in about 30 minutes, and, while most cases will be dealt with in a hospital, it may also be carried out in the general practitioner's surgery with simple equipment.

Requests for reprints should be addressed to: Dr P F Cameron, The Surgery, 60 Northern Rd, Cosham, Portsmouth.

I would like to thank Dr G MacDonagh, consultant, for encouragement; Dr D Hadley, medical assistant, for demonstrating the technique of phenolisation; and Mrs J Simpson for preparing the manuscript.

\section{References}

${ }^{1}$ Palmer BV, Jones A. Ingrowing toenails: the results of treatment. $\mathrm{Br} \mathcal{F}$ Surg $1979 ; 66: 575-6$.

2 Wallace WA, Milne DD, Andrews T. Gutter treatment for ingrowing toenails. Br Med f 1979 ;ii:168-71.

(Accepted 2 fuly 1981) 